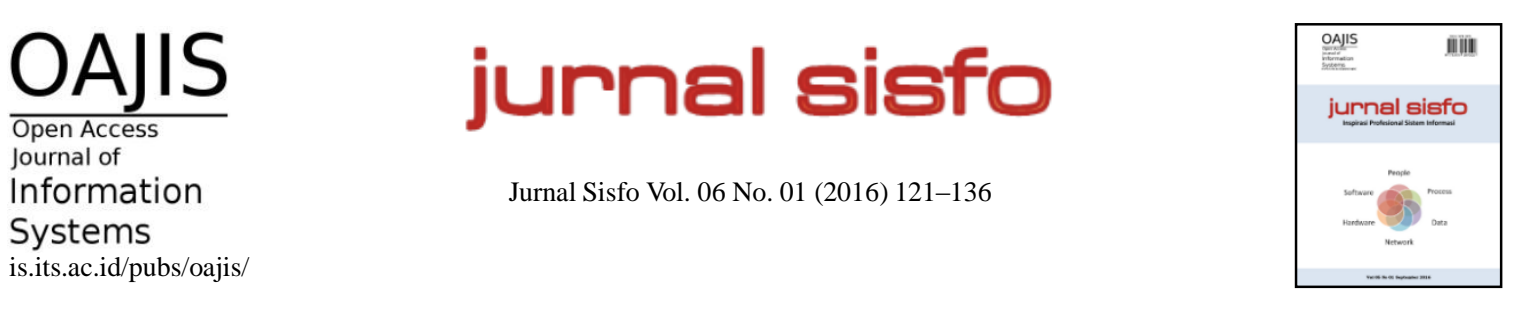

\title{
Pemeringkatan Website Dispendukcapil pada Ibukota Provinsi di Indonesia Berdasarkan Peraturan Depkominfo dan Celah Keamanannya
}

\author{
Yuanita Aulia Chamdini, Bekti Cahyo Hidayanto*, Tony Dwi Susanto \\ Jurusan Sistem Informasi, Fakultas Teknologi Informasi, Institut Teknologi Sepuluh Nopember
}

\begin{abstract}
The implementation of e-government in Indonesia is the utilization of the technology used to help the government business processes more effective and efficient. One of them with the implementation of public services online. This study examines the extent to which the Dispendukcapil website development as well as the level of safety. In the testing phase of data-use tool that has been done by previous research, and also use the tool to determine the level of security of the website. The measuring tool covers all belong Marany research and Jayashree and Depkominfo regulations. Meanwhile, security testing using Acunetix WVS tool and the results obtained into consideration expert judgment to analyze the risks assessment. Results from this study is the evaluation process that reviewed Dispendukcapil website of Handbook Depkominfo and reviewed based vulnerabilities. On the website ranking will eventually be done by each category and based vulnerabilities. So with this study provides suggestions for Dispendukcapil Capital website in the manufacture and maintenance of websites in particular the security for more leverage.
\end{abstract}

Keywords: Website, Dispendukcapil, Depkominfo regulations, Accunetix, WVS, Information Security, Interaction, Transaction, and Integration

\begin{abstract}
Abstrak
Penerapan e-government di Indonesia merupakan pemanfaatan teknologi yang digunakan untuk membantu proses bisnis pemerintah yang lebih efektif dan efisien. Salah satunya dengan penerapan layanan public secara online.

Penelitian ini meneliti sejauh mana tingkat pengembangan website Dispendukcapil serta tingkat keamanannya. Dalam tahapan pengujian data digunakan alat yang telah dilakukan oleh penelitian sebelumnya, dan juga menggunakan tool untuk mengetahui tingkat keamanan website. Alat ukur tersebut mencakup seluruh penelitian milik Marany dan Jayashree serta peraturan Depkominfo. Sedangkan, pengujian keamanan menggunakan tool Acunetix WVS dan hasil yang didapatkan menjadi pertimbangan expert judgement untuk menganalisa tingkat kerawanannya. Hasil dari penelitian ini adalah proses evaluasi website Dispendukcapil yang ditinjau dari Buku Panduan Depkominfo serta ditinjau berdasarkan celah keamanannya. Pada akhirnya akan dilakukan pemeringkatan website berdasarkan masingmasing kategorinya dan berdasarkan celah keamanannya. Jadi dengan adanya penelitian ini memberikan saran bagi website Dispendukcapil Ibukota Provinsi dalam pembuatan dan perawatan website khususnya pada hal keamananya agar lebih maksimal.
\end{abstract}

Kata kunci: Website, Dispendukcapil, Peraturan Depkominfo, Accunetix WVS, Keamanan, Informasi, Interaksi, Transaksi, dan Integrasi

(C) 2016 Jurnal SISFO.

Histori Artikel: Disubmit 25 Juli 2016; Diterima 16 September 2016; Tersedia online 16 September 2016

*Corresponding Author

Email address: bekticahyo@is.its.ac.id (Bekti Cahyo Hidayanto) 


\section{Pendahuluan}

Di era modern seperti saat ini, penggunaan website telah meluas di berbagai bidang. Mulai dari bidang industry, manufaktur, pemerintah, hingga pendidikan [1]. Hal ini menunjukkan sebagai pesatnya perkembangan teknologi informasi dan komunikasi (TIK) khususnya di daerah Indonesia. Seperti contohnya pada bidang pemerintahan, dengan adanya penggunaan website maka setiap daerah akan semakin ketat dalam melakukan penerapan TIK nya untuk berbagi layanan public [2]. Hal ini ditunjukkan dengan meningkatkan kualitas pelayanan public dengan didukung oleh pengggunaan TIK yang telah diatur oleh Inpres No.3 Th 2003 mengenai kebijakan strategi pengembangan e-government.

Salah satu wujud memberikan kualitas pelayanan public yang baik adalah website Dinas Kependudukan dan Pencatatan Sipil (Dispendukcapil) yang bergerak dalam bidang kependudukan yang bertujuan untuk membangun kualitas database kependudukan guna menjamin legalitas dokumen kependudukan yang meliputi Kartu Keluarga (KK), Kartu Tanda Penduduk (KTP), Akta Pencatatan Sipil maupun Surat Keterangan Kependudukan lainnya [3].

Selain itu, Keamanan sistem informasi merupakan hal yang sangat penting dalam membangun sistem infomasi yang terkait dengan online transaction tanpa membocorkan informasi pribadi atau informasi lainnya yang dimiliki oleh masyarakat. Proses penjamin keamanan ini sangat diperlukan masyarakat untuk tetap menjaga kepercayaan masyarakat terhadap sistem e-government yang sedang diimplementasikan di Indonesia. Keamanan dari tampilan website juga perlu dipertimbangkan karena informasi penting yang ditampilkan melalui situs website, apabila tidak dijaga dengan baik, maka seorang hacker akan dapat mengubah informasi tersebut tidak sesuai dengan kenyataan.

Lalu, dengan adanya penerapan website pada kepemerintahan maka Departemen Komunikasi dan Informasi telah mengeluarkan beberapa peraturan mengenai pembuatan website e-government dimana adanya minimal conten yang harus dipenuhi dalam pembuatan website. Sehingga, untuk memaksimal fungsi situs website perlu adanya evaluasi mengenai peraturan depkominfo. Dimana peraturan ini akan dirumuskan menjadi empat kategori yang telah mencakup keseluruhan isi website.

Berdasarkan paparan latar belakang di atas maka hal yang sangat menarik pada penelitian ini adalah adanya evaluasi website Dispendukcapil yang berfokus pada Ibukota Provinsi di Indonesia berdasarkan peraturan Depkominfo dan celah keamanannya. Sehingga hasil akhir dari penelitian ini akan berupa peringkat terbaik diantara website Ibukota. Jadi diharapkan dapat menjadi bahan evaluasi dari website Dispendukcapil yang kedepannya dapat memperbaiki kualitas website yang telah patuh pada peraturan Depkominfo serta kualitas di bidang keamanan agar data yang tersimpan tidak bocor ke dunia maya.

\section{Tinjauan Pustaka/Penelitian Sebelumnya}

Pada bagian ini dijelaskan mengenai teori yang dijadikan sebagai tinjauan pustaka dasar dalam mendukung penelitian ini.

\subsection{Pengertian E-Goverment}

Penerapan e-gov sangat erat kaitannya dengan kondisi internal yang baik dengan pemerintah yang bersangkutan karena akan adanya pemahaman yang ditentukan mengenai sejarah, budaya, pendidikan, politik, dan kondisi ekonomi [4]. E-goverment dapat diaplikasikan pada legislative, yudikatif, atau adminitrasi public untuk meningkatkan efisiensi internal, menyampaikan pelayanan publik, atau proses kepemerintahan yang demokratis. 


\subsection{Dinas Kependudukan dan Catatan Sipil (Dispendukcapil)}

Dinas Kependudukan dan Catatan Sipil (Dispendukcapil) merupakan unsur pelaksanaan Kementrian Dalam Negeri dibidang kependudukan dan pencatatan sipil. Dispendukcapil mempunyai tugas melaksanakan urusan pemerintahan daerah bedasarkan azas otonomi dan tugas pembantuan di bidang kependudukan dan catatan sipil [5].

\subsection{Keamanan Sistem Informasi}

Keamanan sistem informasi merupakan aspek yang utama diperhatikan dalam membangun sebuah sistem agar data-data rahasia yang penting tidak dapat diakses oleh orang lain yang tidak berkepentingan. Lebih lanjut, keamanan sistem informasi adalah suatu upaya untuk mengamankan aset informasi secara tidak langsung dapat menjamin kontuinitas bisnis, mengurangi resiko yang terjadi, mengoptimalkan pengembalian investasi [6].

\subsection{Acunetix Web Vulnerability Scanner}

Accunetix Web Vulnerability Scanner adalah sebuah alat yang dibuat untuk mencari celah keamanan yang pada sebuah aplikasi website dari serangan orang-orang yang tidak bertanggung jawab yang kemungkinan akan menyalahgunakan website tersebut untuk mendapatkan akses illegal ke data dan sistem. Dimana terdapat beberapa kerentanan (vulnerabilities) contohnya SQL Injection, Cross Site Scripting (XSS), dan password yang lemah [7].

\subsection{Pengkategorian Website}

Penelitian yang dilakukan oleh Marany dan Jayashree menyebutkan bahwa terdapat tipe-tipe kategori website secara umum yaitu Informasi, Interaksi, Transaksi, Integrasi, dan e-Society [8]. Namun pada penelitian ini hanya menggunakan 4 kategori saja karena kategori yang terakhir yaitu $E$-Society, tidak akan bisa diuji diwebsite pemerintah di Indonesia. Pada tahapan E-democracy berarti website pemerintah di Indonesia telah dapat digunakan untuk kegiatan politik secara online seperti pemilihan kepala daerah via online voting, dan fasilitas forum untuk kegiatan politik lainnya.

\subsection{Peraturan Depkominfo}

Intruksi Presiden No 3 Tahun 2003 menjelaskan mengenai Menteri Komunikasi dan Informasi dapat mengambil prosedur yang digunakan untuk tugas, fungsi, dan kewenangan masing-masing yang berguna untuk melakukan pengembangan terhadap e-government dengan pedoman pada kebijakan dan strategi nasional. Berikut ada isi (content) minimum yang telah sesuai dengan kriteria yang telah ditetapkan Depkominfo [9].

\subsubsection{Selayang Pandang}

1) Profil SKPD: Profil ini berisikan mengenai sejarah singkat berdirinya SKPD.

2) Visi dan Misi : mengenai visi dan misi dari sebuah SKPD yang harus dicantumkan agar masyarakat mengetahui dengan jelas visi dan misi yang dibawa oleh SKPD.

3) Tupoksi: mengenai tugas pokok dan fungsi dari SKPD yang menjelaskan tentang arahan kerjanya agar masyarakat dapat mengetahui ranah kerja yang dilakukan oleh SKPD tersebut. 


\subsubsection{Pemerintah Daerah}

Struktur Organisasi : mengenai struktur organisasi yang terdapat pemerintahan setempat. Biasanya akan terdapat informasi mengenai nama, alamat, telepon, dan email dari pejabat daerah tersebut.

\subsubsection{Peraturan / Kebijakan Daerah}

1) RENSTRA : dijelaskan tentang rencana strategi yang telah disusun oleh SKPD tersebut. Hal ini berguna sebagai sarana untuk menyosialisasikan kepada masyarakat luas mengenai rencana strategi tersebut

2) LAKIP:Berisi mengenai dokumen pertanggungjawaban kinerja dari SKPD atas rencana strategi maupun rencana tahunan yan telah disusunnya.

\subsubsection{Berita}

1) Artikel Berita : Berita yang dikelurkan oleh pemerintahan akan menjadi acuan penting dalam wartawan local untuk membuat berita untuk surat kabar local.

2) Galeri : Berisikan dokumentasi dari seluruh kegiatan acara yang telah diadakan oleh SKPD tersebut guna sebagai bukti bahwa acara tersebut telah dilaksanankan

\subsubsection{Forum Diskusi}

Pengaduan Online : Masyarakat dapat melakukan pengaduan kepada SKPD yang bersangkutan untuk membantu masalah yang sedang dihadapi.

\section{Metodologi}

Pengerjaan penelitian ini akan melalui beberapa metode. Berikut adalah panduan dalam proses pengerjaan penelitian lebih terarah. Gambar 1 adalah metodologi pengerjaan penelitian.

\subsection{Tahap Persiapan}

Pada tahapan ini dilakukan observasi terkait permasalahan keamanan yang ada di dalam website Dispendukcapil juga dilakukan studi literatur terkait dengan topik yang dibahas pada Inputan pada tahapan ini adalah jurnal, paper dan buku seputar evaluasi keamanan website

\subsection{Penyusunan Alat Ukur Berdasarkan Penelitian Marany dan Panduan Depkominfo}

Tahapan ini dilakukan penyusunan alat ukur yang akan digunakan untuk melakukan cek website Dispendukcapil yang nantinya digunakan untuk menghasilkan peringkat website. Penyusunan ini berdasarkan studi literature dari berbagai referensi yang ada. Sehingga outputannya yang diharapkan berupa alat ukur yang dapat digunakan untuk melakukan pengececkan website berdasarkan peneltian Marany dan Peraturan Depkominfo

\subsection{Memeriksa Website}

Tahapan ini dilakukan dengan melakukan pengecheckan website Dispendukcapil pada Ibukota Provinsi di Indonesia yang berdasarkan penelitian Marany dan Peraturan Depkominfo. Alur memeriksa website dapat dilihat pada Gambar 2. 


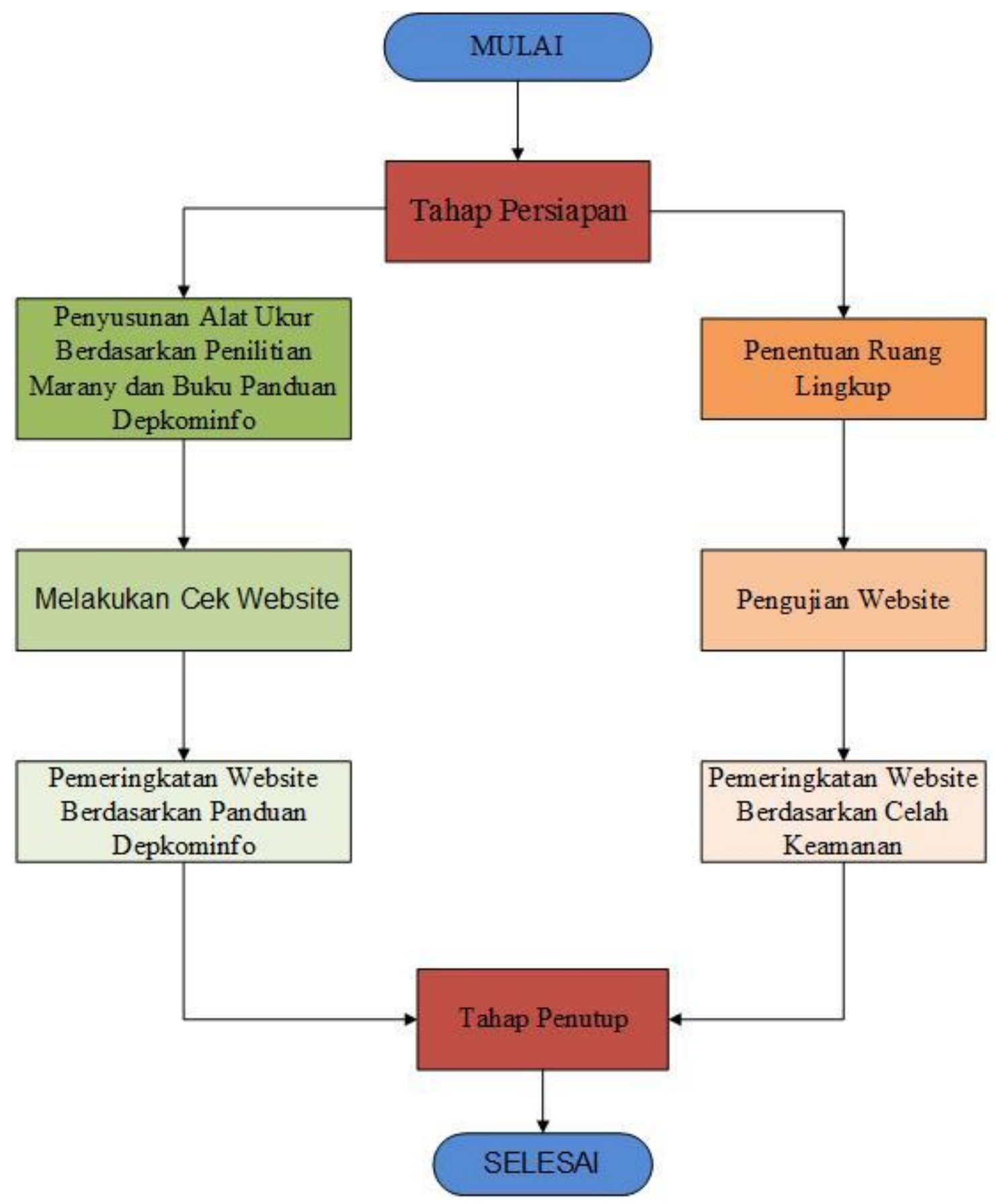

Gambar 1. Alur Metodologi Penelitian

\subsection{Pemeringkatan Website Berdarkan Panduan Depkominfo}

Proses pemeringkatan dengan acuan penelitian milik [10], dimana pada penelitian tersebut menjelaskan bahwa setiap kategori mendapatkan bagian sebanyak $25 \%$. Sehingga outputannya adalah hasil peringkat 
yang telah diteliti tentang kepatuhan akan aturan yang dikeluarkan oleh Depkominfo. Gambar 3 menunjukkan alur pemeringkatan website berdasarkan panduan Kominfo.

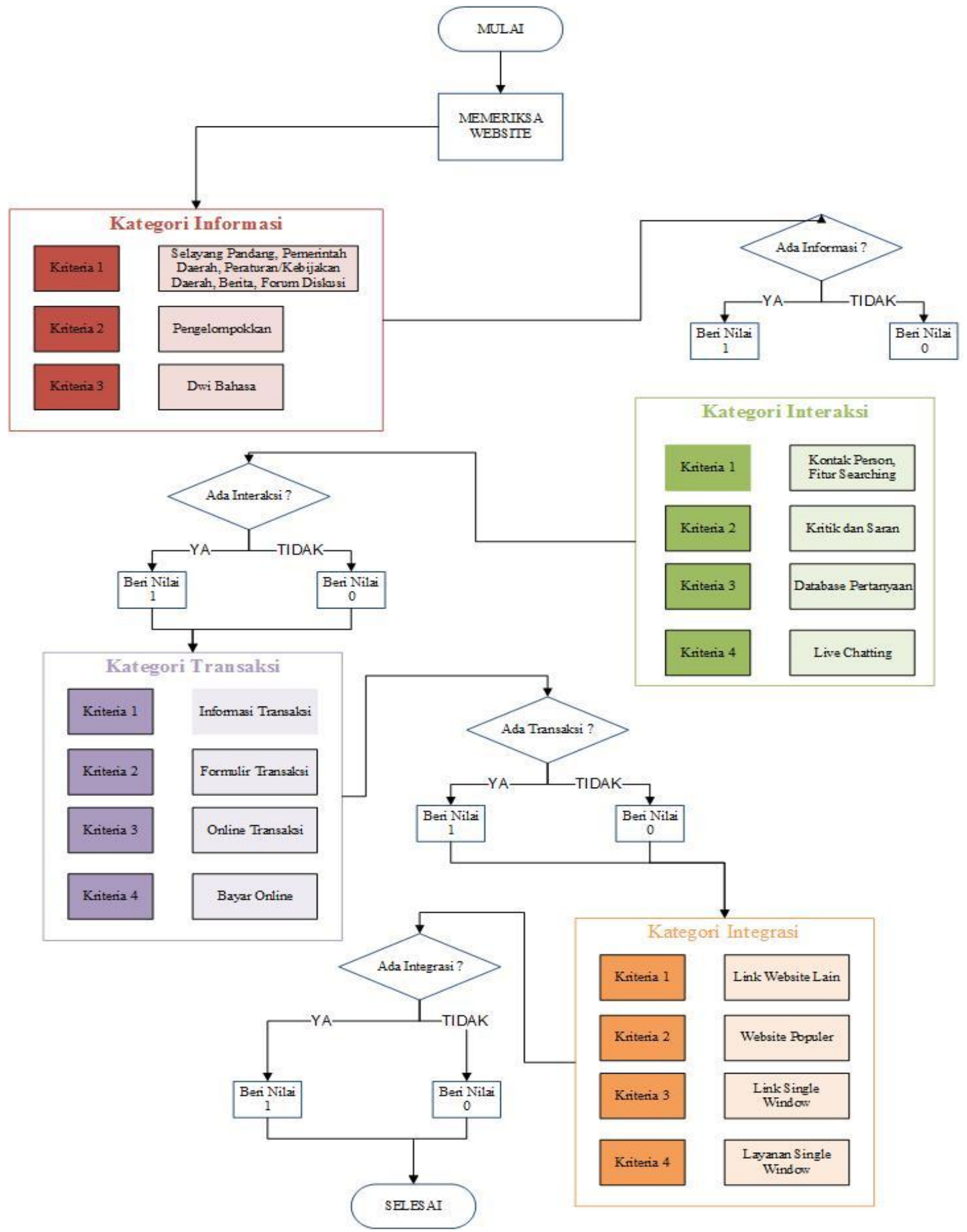

Gambar 2. Flowchart Memeriksa Website 


\subsection{Penentuan Ruang Lingkup}

Tahapan yang dilakukan menentukan ruang lingkup untuk mengetahui segala informasi yang ada pada website yang akan menjadi target pengecheckan. Informasi yang akan diberikan mengenai system operasi, server, dan webserver yang sedang digunakan untuk website Dispendukcapil. Selain itu, pada tahapan ini juga menentukan celah keamanan apa saja yang akan diuji tetapi pada penelitian ini akan diujikan seluruh celah keamanannya

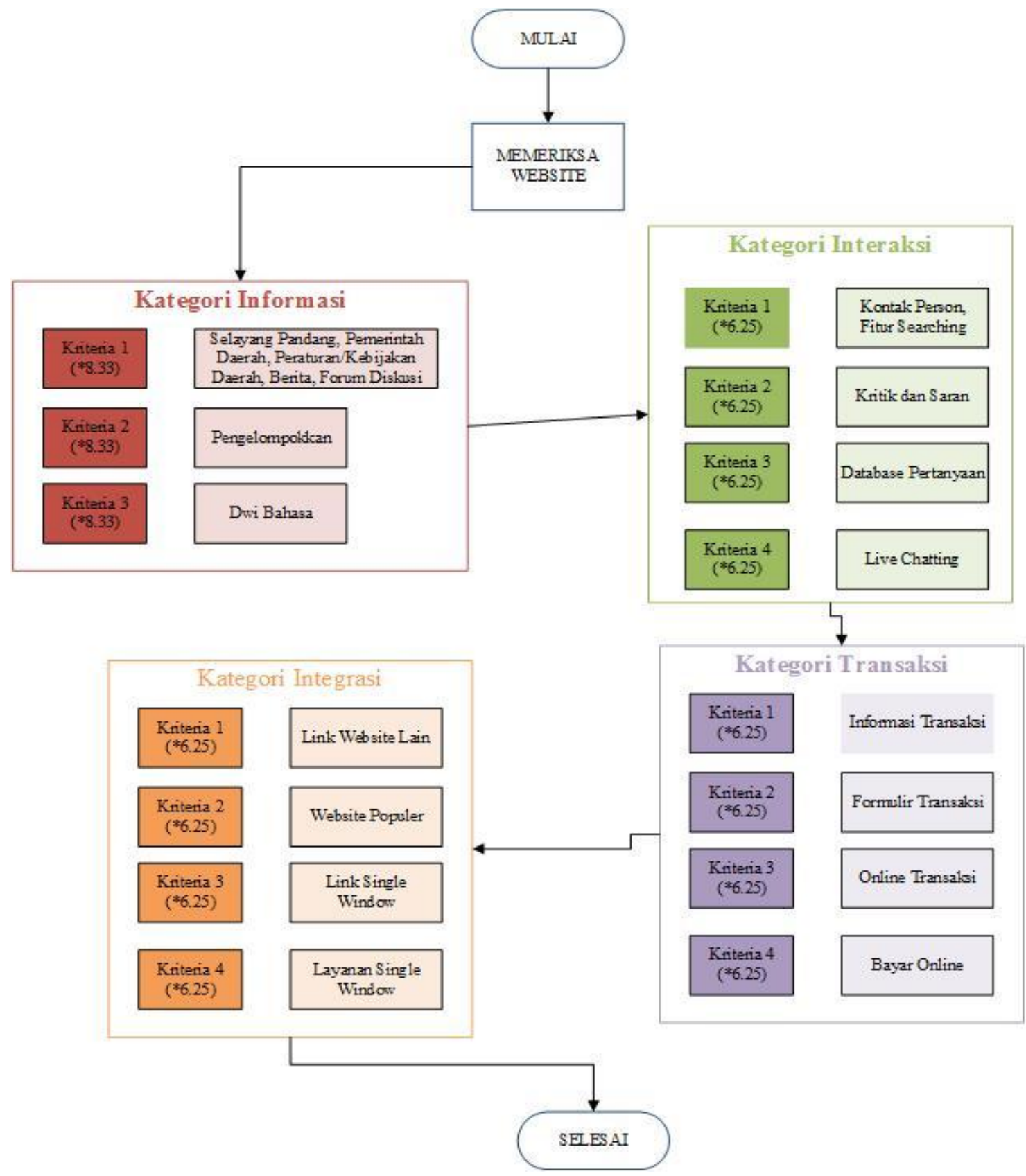

Gambar 3. Flowchart Pemeringkatan Website Berdasarkan Panduan Depkominfo 


\subsection{Pengujian Website}

Tahapan ini dilakukan pengujian data dengan menggunakan bantuan tool Acunetix Web Vulnerability Scanner versi 9.0

\subsection{Pemeringkatan Website Berdasarkan Celah Keamanan}

Pada tahapan ini dilakukan pemeringkatan website berdasarkan hasil pengujiannya. Pengujian dilakukan menggunakan bantuan tool Acunetix WVS. Selanjutnya seluruh tahapan pemeringkatan menggunakan metode AHP.

\subsection{Tahap Penutup}

Pada tahapan akhir ini mulai menyusun kesimpulan dan saran dari hasil pengerjaan laporan ini yang nantinya dapat dijadikan bahan evaluasi bagi Dispendukcapil di Indonesia untuk meningkatkan keamanan agar terhindar dari serangan hacker. Sehingga output dari tahapan ini adalah berupa kesimpulan mengenai permeringkatan website Dispendukcapil pada ibukota provinsi berdasarkan pengkategorian website dan menggunakan metode AHP.

\section{Hasil dan Pembahasan}

Pada tahap ini akan menjelaskan mengenai hasil dan pembahasan penelitian yaitu keluaran dari pengujian website berdasarkan panduan depkominfo dan celah keamanannya. Pada tahap ini akan juga akan menghasilkan pemeringkatan website untuk mengetahui website yang terbaik dan masih kurang baik.

\subsection{Hasil Penelitian Berdasarkan Peraturan Depkominfo}

\subsubsection{Capaian Kriteria Tiap Kategori}

Hasil capaian tingkat pengembangan website yang dapat berfungsi melihat mayoritas level yang dicapai oleh setiap website. Jumlah website yang dilakukan pengujian berjumlah 20 website. Hal ini perlu dilakukan agar dapat memudahkan untuk mengetahui mayoritas capaian tingkat pengembangan website pada tiap kategorinya.

Tabel 1. Capaian Website Dispendukcapil se-Ibukota Provinsi

\begin{tabular}{ccccc}
$\begin{array}{c}\text { Kategori } \\
\text { Nilai }\end{array}$ & Informasi & Interaksi & Transaksi & Integrasi \\
\hline $0-12.5 \%$ & 0 & 1 & 0 & 6 \\
$12.5 \%-25 \%$ & 20 & 19 & 10 & 14 \\
\hline
\end{tabular}

Dari data Tabel 1 dapat diketahui bahwa jumlah website Dispendukcapil yang dapat diakses bekisar 20 website. Hasil capaian yang memiliki lebih dari $12.5 \%$ yang terbanyak pada kategori pertama (informasi) dan kategori kedua (interaksi). Terdapat 20 website yang dapat diakses memiliki nilai lebih dari $12.5 \%$ pada kategori informasi dan interaksi. Jadi berdasarkan Tabel 1 menunjukan bahwa website Dispendukcapil di Indonesia lebih mengarah kategori Informasi dan Interaksi. 


\subsubsection{Peringkat Website Berdasarkan Peraturan Depkominfo}

Berikut adalah tabel yang berisi peringkat website yang dapat diakses 20 website dari 34 provinsi yang memiliki capaian nilai yang terbaik hingga terendah berdasarkan alat ukur yang telah dibuat.

1) Kategori Informasi

Tabel 2. Peringkat Website Kategori Informasi

\begin{tabular}{|c|c|c|}
\hline No & Provinsi & Persentase Skor (\%) \\
\hline \multirow[t]{2}{*}{1} & Papua & 25 \\
\hline & $\begin{array}{c}\text { Sumatera Utara } \\
\text { Sumatera Selatan } \\
\text { DKI Jakarta }\end{array}$ & \\
\hline \multirow[t]{9}{*}{2} & Jawa Timur & 22 20 \\
\hline & Bali & 22.22 \\
\hline & NTB & \\
\hline & Kalimantan Barat & \\
\hline & Sulawesi Utara & \\
\hline & Aceh & \\
\hline & Riau & \\
\hline & Jambi & \\
\hline & Bangka Belitung & \\
\hline \multirow{6}{*}{3} & Kepulauan Riau & 1667 \\
\hline & DI Yogyakarta & 10.01 \\
\hline & Jawa Barat & \\
\hline & Jawa Tengah & \\
\hline & Kalimantan Selatan & \\
\hline & Kalimantan Timur & \\
\hline 4 & Kalimantan Utara & 13.89 \\
\hline
\end{tabular}

2) Kategori Interaksi

Tabel 3. Peringkat Website Kategori Interaksi

\begin{tabular}{ccc}
\hline No & Provinsi & Persentase Skor (\%) \\
\hline 1 & DI Yogyakarta & 25 \\
& Aceh & \\
& Sumatera Utara & \\
Riau & \\
Jambi & 18.75 \\
& Sumatera Selatan & \\
& Jawa Barat \\
& Jawa Tengah \\
Jawa Timur & \\
& Bali \\
& Kalimantan Barat \\
\hline
\end{tabular}




\begin{tabular}{|c|c|c|}
\hline \multicolumn{2}{|r|}{ Kalimantan Selatan } & \\
\hline & Kalimantan Timur & \\
\hline & Kalimantan Utara & \\
\hline & Sulawesi Utara & \\
\hline & Papua & \\
\hline 3 & $\begin{array}{c}\text { Bangka Belitung } \\
\text { Kepulauan Riau } \\
\text { NTB }\end{array}$ & 12.5 \\
\hline 4 & DKI Jakarta & 6.25 \\
\hline
\end{tabular}

3) Kategori Transaksi

Tabel 4. Peringkat Website Kategori Transaksi

\begin{tabular}{|c|c|c|}
\hline No & Provinsi & Persentase Skor (\%) \\
\hline \multirow{10}{*}{1} & Aceh & \multirow{10}{*}{12.5} \\
\hline & Sumatera Utara & \\
\hline & Jambi & \\
\hline & Bangka Belitung & \\
\hline & DKI Jakarta & \\
\hline & DI Yogyakarta & \\
\hline & Jawa Timur & \\
\hline & Bali & \\
\hline & Kalimantan Utara & \\
\hline & Papua & \\
\hline \multirow{8}{*}{2} & Riau & \multirow{8}{*}{6.25} \\
\hline & Sumatera Selatan & \\
\hline & Kepulauan Riau & \\
\hline & Jawa Barat & \\
\hline & Jawa Tengah & \\
\hline & Kalimantan Barat & \\
\hline & Kalimantan Timur & \\
\hline & Sulawesi Utara & \\
\hline \multirow{2}{*}{3} & NTB & \multirow{2}{*}{0} \\
\hline & Kalimantan Selatan & \\
\hline
\end{tabular}

4) Kategori Integrasi

Tabel 5. Peringkat Website Kategori Integrasi

\begin{tabular}{ccc}
\hline No & Provinsi & Persentase Skor (\%) \\
\hline 1 & Jawa Timur & 25 \\
& Aceh & \\
2 & Sumatera Utara & 12.5 \\
& Riau & \\
\hline
\end{tabular}




\begin{tabular}{c} 
Sumatera Selatan \\
Bangka Belitung \\
DI Yogyakarta \\
Jawa Barat \\
Jawa Tengah \\
Bali \\
NTB \\
Kalimantan Barat \\
Kalimantan Timur \\
Papua \\
Kepulauan Riau \\
DKI Jakarta \\
Kalimantan Selatan \\
Kalimantan Utara \\
Sulawesi Utara \\
\hline
\end{tabular}

\subsection{Hasil Penelitian Berdasarkan Celah Keamananya}

\subsubsection{Nilai Bobot Per Vulnerability}

Pada tahapan ini akan menghasilkan bobot yang sesuai dengan vulnerability yang telah ditemukan sebelumnya. Pemberian bobot ini menggunkan metode AHP yang sebelumnya menyebar kuisioner kepada dua orang expert judgement yang telah ahli dalam bidang keamanan jaringan. Lalu akan dikalikan dengan hasil klaster yang telah dibahas pada sebelumnya. Nilai bobot untuk tiap celah keamanan dapat dilihat pada Tabel 6.

Tabel 6. Nilai Bobot Per Vulnerability

\begin{tabular}{|c|c|c|}
\hline No & Vulnerability & Nilai Bobot \\
\hline 1 & Apache 2.2 .14 mod_isapi Dangling Point & 0.01 \\
\hline 2 & Blind SQL Injection & 0.02 \\
\hline 3 & CRLF injection/HTTTP response splitting & 0.02 \\
\hline 4 & Configuration file source code discloure & 0.02 \\
\hline 5 & Cross Site Scripting & 0.03 \\
\hline 6 & Directory traversal & 0.02 \\
\hline 7 & File Inclussion & 0.03 \\
\hline 8 & HTTP parameter pollution & 0.04 \\
\hline
\end{tabular}




\begin{tabular}{|c|c|c|}
\hline No & Vulnerability & Nilai Bobot \\
\hline 9 & jQuery cross site scripting & 0.02 \\
\hline 10 & Plupload cross-site scripting vulnerability & 0.02 \\
\hline 11 & Script source code discloure & 0.03 \\
\hline 12 & SQL Injection & 0.03 \\
\hline 13 & Server side request forgery & 0.02 \\
\hline 14 & Session fixation & 0.03 \\
\hline 15 & Weak password & 0.03 \\
\hline 16 & Apache $2 . x$ version older & 0.01 \\
\hline 17 & Apache httpd remote denial of service & 0.02 \\
\hline 18 & Apache httpOnly cookie disclosure & 0.03 \\
\hline 19 & Login page password-guessing attack & 0.02 \\
\hline 20 & Backup Files & 0.01 \\
\hline 21 & Basic authentication over HTTP & 0.02 \\
\hline 22 & Directory Listing & 0.02 \\
\hline 23 & Error message on page & 0.01 \\
\hline 24 & Fantastico filelist & 0.01 \\
\hline 25 & HTML form without CSRF protection & 0.02 \\
\hline 26 & Insecure transition from HTTP to HTTPS in form post & 0.01 \\
\hline 27 & PHP hangs on parsing particular strings as floating point & 0.02 \\
\hline 28 & Reverse proxy bypass & 0.01 \\
\hline
\end{tabular}




\begin{tabular}{|c|c|c|}
\hline No & Vulnerability & Nilai Bobot \\
\hline 29 & Source code discloure & 0.04 \\
\hline 30 & User credentials are sent in clear text & 0.03 \\
\hline 31 & Application Firewall detected & 0.02 \\
\hline 32 & Clickjacking: X-Frame-Options header missing & 0.02 \\
\hline 33 & Documentation file & 0.02 \\
\hline 34 & File upload & 0.01 \\
\hline 35 & Login page password-guessing attack & 0.01 \\
\hline 36 & OPTIONS method is enabled & 0.01 \\
\hline 37 & Possible sensitive & 0.01 \\
\hline 38 & Session Cookie & 0.02 \\
\hline 39 & Slow response time & 0.01 \\
\hline 40 & TRACE method is enable & 0.01 \\
\hline 41 & Broken Links & 0.02 \\
\hline 42 & Content type is not specified & 0.02 \\
\hline 43 & Email address found & 0.01 \\
\hline 44 & Error page web server version discloure & 0.02 \\
\hline 45 & Google Hacking Database & 0.02 \\
\hline 46 & Password type input with auto-complete enabled & 0.02 \\
\hline 47 & Possible internal IP address disclosure & 0.03 \\
\hline 48 & Possible server path disclosure (Unix) & 0.03 \\
\hline
\end{tabular}




\begin{tabular}{lcc}
\hline No & Vulnerability & Nilai Bobot \\
\hline 49 & Possible username or password disclosure & 0.03 \\
\hline
\end{tabular}

\subsubsection{Perigkat Website Berdasarkan Celah Keamanan}

Tabel 7 berisi peringkat website yang dapat diakses sebanyak 20 website dari 34 provinsi yang ada.

\begin{tabular}{|c|c|c|}
\hline No & Provinsi & Total Skor \\
\hline 1 & Kalimantan Selatan & 0.03 \\
\hline 2 & Yogyakarta & 0.05 \\
\hline 3 & Papua & 0.10 \\
\hline 4 & Jawa Tengah & 0.67 \\
\hline 5 & Manado & 0.78 \\
\hline 6 & Kalimantan Timur & 0.89 \\
\hline 7 & Sumatera Selatan & 0.97 \\
\hline 8 & NAD & 1.17 \\
\hline 9 & Kalimantan Utara & 2.02 \\
\hline 10 & Jawa Barat & 2.95 \\
\hline 11 & Kepulauan Riau & 3.06 \\
\hline 12 & Jambi & 3.08 \\
\hline 13 & Kalimantan Barat & 5.35 \\
\hline 14 & Bali & 9.01 \\
\hline 15 & Riau & 10.05 \\
\hline
\end{tabular}




\begin{tabular}{|c|c|c|}
\hline 16 & Bangka Belitung & 10.96 \\
\hline 17 & Jawa Timur & 11.86 \\
\hline 18 & NTB & 13.29 \\
\hline 19 & DKI Jakarta & 22.94 \\
\hline 20 & Sumatera Utara & 36.46 \\
\hline
\end{tabular}

Berdasarkan Tabel 7, bahwa website Dispendukcapil yang paling aman dari serangan hacker pada Provinsi Kalimantan Selatan yaitu website Dispendukcapil Banjarmasin, sedangkan website yang paling rawan diserang oleh hacker terdapat pada website Dispendukcapil Provinsi Sumatera Utara.

\section{Kesimpulan}

Bab ini akan menjelaskan kesimpulan dari penelitian ini, beserta saran yang dapat bermanfaat untuk perbaikan di penelitian selanjutnya

\subsection{Simpulan}

Berdasarkan pada hasil penelitian yang telah dilakukan, maka didapatkan kesimpulan dari inni antara lain seperti berikut :

1) Jumlah provinsi di Indonesia sebanyak 34 provinsi. Terdapat 2 provinsi yang memiliki website resmi tetapi tidak dapat diakses, lainnya sekitar 12 provinsi yang tidak memiliki website resmi. Jadi total website yang dapat diakses dan diuji sebanyak 20 website.

2) Dari hasil analisa tingkat pengembangan website Dispendukcapil dapat disimpulkan lebih mengarah pada kategori interaksi dan kategori integrasi. Hal itu ditunjukan dengan 20 website yang lebih mengarah pada kategori informasi dan kategori interaksi

3) Peringkat website Dispendukcapil berdasarkan masing-masing kategori yaitu
a. Kategori Informasi
- Terbaik : Papua (Skor : 41.65)
- Terendah : Kalimantan Utara (Skor : 16.66)

b. Kategori Interaksi

- Terbaik : DI Yogyakarta (Skor : 25)

- Terendah : DKI Jakarta (Skor : 6.25)

c. Kategori Transaksi

- Terbaik : NAD, Sumatera Utara, Jambi, Bangka Belitung, DKI Jakarta, DI Yogyakarta, Jawa Timur, Bali, Kalimantan Utara, Papua (Skor : 12.5)

- Terendah : Kalimantan Selatan, NTB (Skor : 0)

d. Kategori Integrasi

- Terbaik : Jawa Timur (Skor : 25)

- Terendah : Kepulauan Riau, DKI Jakarta, Kalimantan Selatan, Kalimantan Utara Sulawesi Utara (Skor : 6.25)

4) Peringkat website berdasarkan celah keamananya yang pertama pada provinsi Kalimantan Selatan dengan jumlah skor 0.03, dan peringkat kedua pada Yogyakarta dengan jumlah skor 0.05

5) Permasalahan umum yang dihadapi pada saat pengerjaan diantaranya : 
a. Pencarian situs website Dispendukcapil yang belum familiar sehingga membutuhkan waktu lama

b. Masih banyak Ibukota Provinsi di Indonesia yang belum memiliki website Dispendukcapil

c. Website Dispendukcapil masih banyak yang tidak sesuai dengan konten yang ditentukan

d. Hasil kuisioner dari dua responden dapat dikatakan berbeda jauh satu sama lainnya.

\subsection{Saran}

Dari pengerjaan ini terdapat hal-hal yang dapat diperbaiki lagi untuk penelitian selanjutnya, antara lain :

1) Pada penelitian ini, ruang lingkup yang diteliti kurang luas

2) Tool yang digunakan pada penelitian ini masih menggunakan Acunetix WVS saja, sebaiknya dilain waktu menggunakan tool yang lebih banyak

3) Penelitian mengenai keamanan dan konten minimum e-goverment website Dispendukcapil ini dapat dikembangka lagi dengan meneliti tingkat availability website, kualitas website, dll.

\section{Daftar Rujukan}

[1] Junaidi, "Dukungan E-Government Dalam Upaya Peningkatan Kualitas Pelayanan Publik Di Era Otonomi Daerah," Proceeding Simposium Nasional Otonomi, 2011.

[2] Donny, "Fakta dan Kondisi e-Government di Indonesia," ICT Watch, 2004

[3] Dispendukcapil Surabaya, "Layanan Dispendukcapil," Januari 2016. [Online]. Available: http://dispendukcapil.surabaya.go.id/layanan. [Accessed Januari 2016].

[4] Indrajit, "Pengertian E-Goverment Menurut Para Ahli," 2006.

[5] Dispendukcapil Surabaya, "Tugas Pokok dan Fungsi," Januari 2016. [Online]. Available: http://dispendukcapil.surabaya.go.id/tentang-kami/83-tugas-pokok-dan-fungsi. [Accessed Januari 2016].

[6] Sarno, "Keamanan Sistem Informasi," 2010. [Online]. Avalible: http://www.sarnoilmu.com [Accessed Februari 2016].

[7] Acunetix, "Web Application Security," 2015. [Online]. Available: http://www.accunetix.com. [Accessed Januari 2016].

[8] S. Jayashree and G. Marthandan, "Government to E-government to E-society," Journal of Applied Sciences, pp. 2205-2210, 2010.

[9] D. P. d. Kelautan, "Kerangka Acuan Kerja Pembuatan dan Pengelolaan Database SKPD," Pemerintah Kabupaten Probolinggo, Kabupaten Probolinggo, 2015.

[10] F. Makoza, "The Level of E-government Implementation: Case of Malawi”, Electronic Journal of e-Government, 2013 